Portland State University

PDXScholar

10-10-1994

\title{
Temporal Characteristics of Words Surrounding a Moment of Stuttering
}

Janice Kaye Young

Portland State University

Follow this and additional works at: https://pdxscholar.library.pdx.edu/open_access_etds

Part of the Speech and Rhetorical Studies Commons

Let us know how access to this document benefits you.

\section{Recommended Citation}

Young, Janice Kaye, "Temporal Characteristics of Words Surrounding a Moment of Stuttering" (1994). Dissertations and Theses. Paper 4890.

https://doi.org/10.15760/etd.6766

This Thesis is brought to you for free and open access. It has been accepted for inclusion in Dissertations and Theses by an authorized administrator of PDXScholar. Please contact us if we can make this document more accessible: pdxscholar@pdx.edu. 
The abstract and thesis of Janice Kaye Young for the Master of Science in Speech Communication: Speech and Hearing Science were presented October 10, 1994, and accepted by the thesis committee and the department.

COMMITTEE APPROVALS:
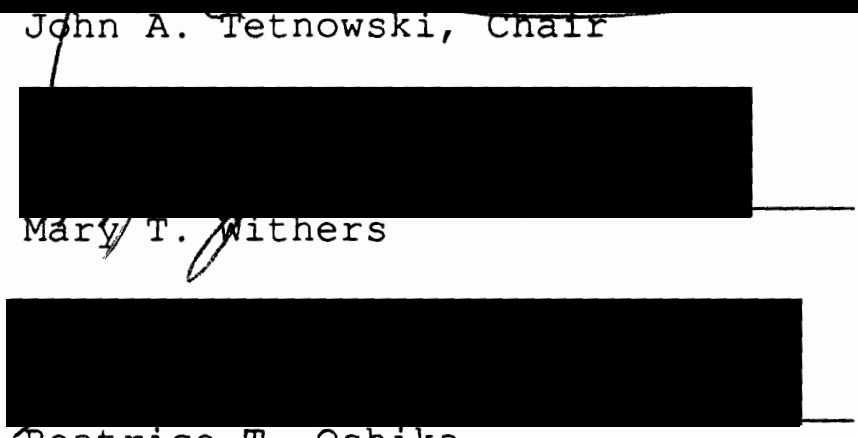

Beatrice T. Oshika

Representative of the office of Graduate Studies

DEPARTMENT APPROVAL:

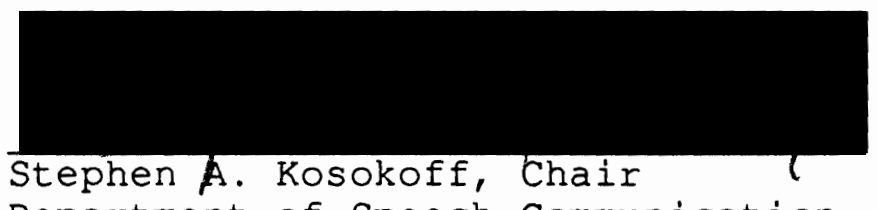

Department of Speech Communication

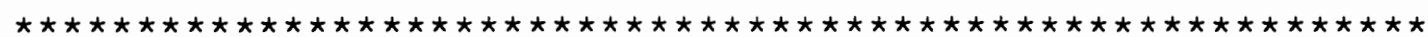

ACCEPTED FOR PORTLAND STATE UNIVERSITY BY THE LIBRARY 


\begin{abstract}
An abstract of the thesis of Janice Kaye Young for the Master of Science in Speech Communication: Speech and Hearing Science presented October 10, 1994.
\end{abstract}

Title: Temporal Characteristics of Words Surrounding a
Moment of Stuttering

Past theories have shown that stuttering results from a breakdown in the speaker's accurate timing of movement from one sound to the next. The efficacy of timing therapies is based on the proposal that stuttering diminishes as the amount of planning time for the phonetic voice-onset coordinations increases (Perkins, Bell, Johnson \& Stocks, 1979). Acoustic information as to the parameters of the timing breakdown is critical to designing fluency facilitation and stuttering treatment programs.

The present research investigated differences in word durations in the vicinity of the stuttered moment. Durations of words immediately preceding and following the stutter were examined and compared to the exact words of a corresponding fluent sample from the same speaker. Stimulus material consisted of 83 phonetically balanced 
sentences read twice by each subject with an imposed 30 minute break between readings to minimize adaptation effects.

Data analysis consisted of spectrographic measurement of durations of words (in msec.) immediately preceding and following the stuttered word and comparison of durations of the same words from the same speaker's fluent production sample. Word durations before the stuttered sample (BSTUT) were compared to word durations before the nonstuttered sample (BNSTUT). A second comparison looked at the duration of a word after a stuttered word (ASTUT), and that of the nonstuttered sample (ANSTUT).

One sample, two-tailed t-tests determined the existence of significant differences at the .05 level of confidence in word durations both preceding and following the stuttered moment when compared to word durations of the fluently produced corresponding match. Word duration patterns are consistent with those found by Viswanath (1989) and suggest that the anticipatory effect of the disruption on word duration is strong followed by a recovery period after the stuttered moment.

In conclusion, this finding is consistent with theories suggesting that stuttering is a disorder of timing and supports the efficacy of timing therapies in the management of fluency programs (Andrews, Howie, Dosza \& Guitar, 1982; Andrews, Guitar \& Howie, 1980, Brayton \& 
Conture, 1978, Ingham, Montgomery \& Uliana, 1983). There is need for additional research to corroborate present findings. 
TEMPORAL CHARACTERISTICS OF WORDS SURROUNDING

A MOMENT OF STUTTERING

by

JANICE KAYE YOUNG

A thesis submitted in partial fulfillment

of the requirements for the degree of

\author{
MASTER OF SCIENCE \\ in \\ SPEECH COMMUNICATION: \\ SPEECH AND HEARING SCIENCE
}

Portland State University

1994 


\section{ACKNOWLEDGEMENTS}

I gratefuily acknowledge three very special mentors in the field of stuttering. Thank you, Dr. Casteel, for being instrumental in my decision to enter the field of speech language pathology. Your help early on was critical to making this career choice a reality. Thank you, Dr. Tetnowski, for all the time spent advising me as the project progressed, and for providing encouragement when needed. Thank you, Mary T., for all the editing, reliability help, and for good words along the way.

Thank you, Dr. Oshika, for adding linguistic expertise to the committee and for your willingness to include yet another thesis defense in your full schedule.

I am especially grateful to a very helpful husband and family. Hats off to a great rooting section: To my leading man, Jerry; four understanding daughters, Jami, Julie, Jeannie, and Joy; two sons-in-love, John and Matt; grandchildren Brenton, Taylor, and Ethan; and sister, Judy, all of whom had less a share of my time and attention on returning to school.

And to Dad, who believed in me but didn't live to see the finish, my love always. 
TABLE OF CONTENTS

PAGE

ACKNOWLEDGEMENTS . . . . . . . . . . . . . . . . . iii

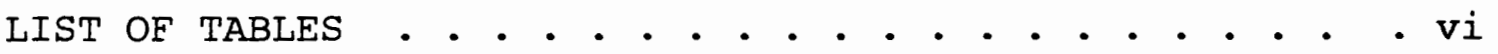

LIST OF FIGURES • • • • • • • • • • • • • • • • • • vii

CHAPTER

I BACKGROUND AND INTRODUCTION

Statement of Purpose . . . . . . . . . 3

Definition of Terms . . . . . . . . 4

II REVIEW OF THE LITERATURE • • • • • • • • • • 6

Studies Based On Listener Judgments . . 7

Observed Differences Between Stuttered

and Fluent Speech . . . . . . . . . 12

Acoustic Variables . . . . . . . 12

Linguistic Variables . . . . . . . 20

Rationale For Acoustic Investigation . . . .25

II METHODS AND PROCEDURES . . . . . . . . . . 28

Introduction . . . . . . . . . . 28

Subjects • . . . . . . . . . . . . . 28

Original study

present Study 
Recording Procedures . . . . . . . . . . 29

Stimulus Materials . . . . . . . . . . . . 29

Identification of Stuttering Moments . • . .31

Reading Errors . . . . . . . . . . . . 32

Excluded Data . . . . . . . . . . . 32

Acoustic Analysis Procedures . . . . . . . . . 33

Reliability . . . . . . . . . . . . . . . . 6

IV RESULTS AND DISCUSSION • • • • • • • • • • 37

Descriptive Data . . . . . . . . . . . 37

Duration Analysis

Reliability

Discussion . . . . . . . . . . 41

V SUMMARY AND IMPLICATIONS . . . . . . . . . . . . 45

Summary • . • • • • • • • • • • • 45

Implications . . . . . . . . . . . . . . . 7

Research Implications

Clinical Implications

REFERENCES 50

APPENDIX . . . . . . . . . . . . . . . . 56

A SENTENCES FOR PHONETIC INVENTORY . . . 62

B DATA CORPUS FOR SUBJECT NM • • . . . 62

C DATA CORPUS FOR SUBJECT DS . • • • 68 


\section{LIST OF TABLES}

TABLE

PAGE

I Components Included in the Configuration of the System II Hardware . . . . . . . . . . . 33

II Results of a T-Test Comparing Word Duration Differences Before a Stuttered Word With Those Occurring Before a Non-Stuttered Word . . . . 38

III Results of a T-Test Comparing Word Duration Differences After a Stuttered Word With Those Occurring After a Non-Stuttered Word . . . . 39 
LIST OF FIGURES

FIGURE

PAGE

I Diagram Illustrating the Configuration of the System II Hardware . . . . . . . . . . . 34 
CHAPTER I

BACKGROUND AND INTRODUCTION

Most listeners have little difficulty recognizing perceptually the speech disruptions in those who stutter, especially as the severity of their disorder increases. On the other hand, it is very difficult to judge the exact moment within an utterance where stuttering begins and ends. Some researchers believe that stuttering should not be viewed as a discrete moment, but rather constitutes a spread effect throughout an utterance (Sacco \& Metz, 1989; Wendahl \& Cole, 1961; Williams, 1957; Viswanath, 1989).

Others refer to stuttering as though it were confined to a singular instant of disruption (Few \& Lingwall, 1972; Johnson, 1933). They perceive the speaker stuttering on words or between words, but often disagree as listeners as to whether and where the disruption occurred (Cordes, Ingham, Frank \& Ingham, 1992).

What is it precisely that makes the fluent speech of those who stutter different from their own nonfluent utterances? Clinicians and speech/language pathologists hold different opinions as to what constitutes a nonfluent utterance. There are many definitions and types of stuttering (repetitions, revisions, incomplete phrases, 
broken words, and prolonged sounds). Clinically, much disagreement exists as to exactly when these types of disruptions begin and where they end.

Other variables have an effect on fluency. For example, acoustic variables such as fundamental frequency, number of pauses, durations, and speech rate signal the listener that changes in fluency are about to occur. Linguistic variables such as position of the stuttered word within an utterance and syntactic characteristics of the disrupted word also appear to have an effect.

In observing and identifying moments of stuttering, listener judges perceive subtle cues of the forthcoming disruption. They have a "feeling" that stuttering is about to occur, but are not certain why. A gray area exists as to what is happening before and after the stuttered moment spanning the continuum between fluent and nonfluent speech.

Perceptual detection and agreement appears to be inadequate to examine this continuum of the speech signal (Cordes, Ingham, Frank \& Ingham, 1992). Acoustic, rather than perceptual methods are more precisely equipped to reveal the parameters of these disruptions and to document by spectrographic analysis where the disruption begins to build and when its effects are spent. 
STATEMENT OF PURPOSE

The purpose of this study was to acoustically examine and objectively measure the spread effects of the stuttering moment, specifically word durations, in the vicinity of the disruption. An answer was sought to the following question: Is there acoustic evidence (different word durations) of the spread effect on words surrounding the stuttered moment? The null hypothesis states that there will be no acoustic evidence of the spread effect surrounding the stuttered moment. 


\section{DEFINITION OF TERMS}

The following terms used throughout this study are more specifically defined below:

Fundamental Frequency: The fundamental frequency (Fo) of the human voice is a one-to-one relationship with the rate of vocal fold vibration which is expressed in cycles per second $(\mathrm{Hz})$, and is the physical correlate to pitch. Fo analysis is compatible with attempts to investigate speech production prior to the onset of overt stuttering moments.

Moment of Stuttering: The moment of stuttering, for the purposes of this paper, consisted of behaviors outlined in the Riley stuttering Severity Instrument (SSI) (Riley \& Riley, 1983) to include "repetitions or prolongations of sounds or syllables (including silent prolongations)." Behaviors such as rephrasing, tense pauses, and repeating whole words of more than one syllable were not counted as moments of stuttering.

Prolongation: A tonic stuttering spasm in which respiratory, phonatory and/or articulatory movement precedes at a slowed, elongated and usually tense level. Prolongations can either be voiced or unvoiced.

Repetition: A clonic stuttering spasm in which alternating contraction and relaxation of speech musculature results in whole-word, part-word, phoneme, and syllable repeats, or repetitive articulatory postures. 
Spread or Vicinity Effect: A term used to describe the effect of a stuttered word on surrounding fluent speech. The effect of concern for this study was specifically, changes in the durations (in msecs) of words in the immediate vicinity of the stuttered moment.

Spectrogram: A voice print (the screen output of a spectrograph) on which phonemes, the smallest units of speech, appear in distinctive patterns useful for acoustic analysis of the speech signal.

Tense Pause: A disruption judged to exist between part-words, words, and nonwords when at the between point in question there are barely audible manifestations of heavy breathing or muscular tightening.

Vowel neutralization: Substitution of the schwa for a correct vowel in repetition sequences, as in (puh-puh-pete for pe-pe-pete). The quality of the vowel is more neutral during stuttering than when spoken in fluent speech.

Adaptation: The decline in stuttering frequency that accompanies consecutive oral readings of the same material. 


\section{CHAPTER II}

\section{REVIEW OF THE LITERATURE}

Marcel Wingate (1964) defined the core features of stuttering as: "a) Disruption of the fluency of verbal expression, which is b) characterized by involuntary, audible or silent, repetitions or prolongations in the utterance of short speech elements, namely: sounds, syllables, and words of one syllable. These disruptions

c) usually occur frequently or are marked in character and d) are not readily controllable (p. 488)." Perkins (1983, 1984) described stuttering as an involuntary loss of control in which the speaker is unable to maintain the forward flow of speech. Van Riper's (1982) description of the speaker's feeling of being "stuck" during a block or in anticipation of a target word lends support to the concept of involuntary loss: "For a moment he or she feels impotent or out of control (p. 122)." Perkins' (1984) comments regarding these moments, however, suggested that the characteristics of stuttering moments are not clearly distinguished from nonstuttered disfluencies, a distinction between fluent speech maintained by voluntary control and that which is automatic: "It is these moments about which we gather 
physiologic and acoustic data on the nature of stuttering (p. 432 )."

The primary concern of the present investigation was to quantify through acoustic data, measurable changes in the durations (if any) which occurred in words surrounding the stuttered moment. In this section the investigator will: 1) briefly review historical studies which differentiate fluent and nonfluent subjects on a perceptual basis; 2) discuss speech characteristics used to discern the fluent speech of normal and stuttering speakers; and 3) present a rationale for acoustic investigation of word durations.

\section{STUDIES BASED ON LISTENER JUDGMENTS}

Williams (1957) believed that stuttering affects all the speech in an utterance. He contended that effects are not exclusive to only the stuttering moment, but that stuttering presents a continuum of psychological and physical influence throughout the utterance. His contention that even the fluent speech of those who stutter deviates from normal speech behavior resulted in investigative research to confirm or deny the theory.

Wendahl and Cole (1961) used eight adult males who stuttered, matched for age and reading proficiency with eight fluent speakers to determine if naive listeners could separate speakers based on an audio-taped oral reading sample from which stuttered words had been cut. The fluent 
speakers' tapes were edited in a similar manner such that for each matched pair of speakers, the same words were cut and the same pause length inserted. Other errors (reading errors, revisions, and mispronunciations) were also deleted from both matched sets. Criteria for the sample were two fold: 1) Four sentences per subject be at least eight words in length, and 2) fluent speech both precede and follow each moment of stuttering. However, one fourth (16 of the 64 sentences) of the data did not meet the criteria due to the location of the stuttering moment. Order of presentation (fluent or stuttered sample first) did not vary within a matched pair, but order was random between pairs overall. Judges were told that either speaker in a pair, neither speaker in a pair, or both speakers may be nonfluent. On the basis of listener perception, 30 judges were able to separate fluent and nonfluent speakers according to rate, strain, and rhythm cues. Based on their study, the conclusion was made that stuttering affects not only the moment itself, but surrounding speech as well and that fluent and stuttered portions are easily differentiated, even though the exact moment of stuttering is not heard. Three years later, Young (1964) replicated the Wendahl and Cole study using the original tape with new judges and a different method of statistical analysis. It had been unclear if in the original study sentences of speaker pairs had been presented to judges in exact sequence or if they 
were randomly distributed throughout the tape among those of other pairs. On receiving the tape to replicate the study, Young found the phrases from speaker pairs were always in sequence. Original instructions were given to the new set of judges. Due to the binary nature of the determination, probability of guessing correctly was 50 per cent. For 43 listeners, the binomial probability limits were 13 and 30 to establish statistical significance. Within these limits, less than 13 stutterer judgments would identify a nonstutterer; 30 or more a stutterer, with a .01 level of confidence. Using these methods to analyze the data, young was unable to conclude that fluent speech of stutterers is easily differentiated from that of nonstutterers.

Few and Lingwall (1972) analyzed the fluent speech of 14 stutterers and found no evidence in listener judgments that the fluent speech of stutterers is either unique or easily identifiable. As in Young's study, all judges were graduate students in speech pathology. Based on 10 second fluent speech samples, listeners judged speaking rate, pause time and whether or not they believed the sample was that of a stutterer or a nonstutterer. A seven-point scale was used in determining the rate of speech ("1" being slow; "7", fast ). Listeners regarded speaking rates of stutterers as slower than nonstutterers, but results failed to reach statistical significance for either rate or identification judgments. Although stutterers produced fewer phonemes in 
fluent segments and displayed slightly higher pause time values, differences were not significant at the .05 level. It was concluded that "the concept of stuttering behavior as intermittent and discrete responses surrounded by essentially normal speech appears to be justified (p. 362)." Ingham \& Packman (1978) intermingled the speech samples of nine treated stutterers with that of fluent controls matched for sex and age to determine if their speech was judged to be significantly different according to features such as prosody, rate, fluency, and naturalness following instruction in prolonged speech techniques. No significant differences were found on this basis, but when judges were asked to determine speech normalcy under forced-choice conditions (deciding which sample in the pair belonged to a stutterer), the stutterers' samples received significantly more "abnormal" judgments. These positive results lend support to Wendahl and Cole's (1961) conclusion that stutterers and fluent subjects are easily differentiated. Runyan \& Adams $(1978,1979)$ used 20 sophisticated (1978) and 20 unsophisticated (1979) judges to determine among two speech samples presented which belonged to a stuttering speaker. Subjects (matched for sex and age with fluent controls), were both successfully and partially treated using one of several therapy methods and rated as mild, moderate or severe prior to therapy. Sophisticated judges were graduate students of speech pathology or 
audiology compared to the secretaries, laborers, businessmen, housewives and nurses comprising the unsophisticated listener group. Results indicated that the fluent speech of stutterers (whether partially or successfully treated) was perceived as different than normal when judged by both sophisticated and unsophisticated listeners. It was also determined that the severity of the disorder varied proportionately with the amount of stuttering.

The findings of Metz, Schiavetti and Sacco (1990) suggest that perceptual differences in speech naturalness were clearly evident between recovered stutterers and normal speakers. Since overall speaking rate changes in relation to voice onset time, vowel durations, number of pauses, etc., Metz. et al. advise limiting the variables that determine the perception of speech naturalness by listeners in order to accurately judge differences between recovered stutterers and normal subjects. Therefore, it is important to note that for the purposes of this study, one variable was selected: word duration, as measured specifically by voice onset/offset time.

To summarize, researchers disagree whether the fluent speech of stutterers differs from that of normal speakers. Based on listener judgments, investigative studies have found evidence both to support and refute the proposal that differences exist. Reliance solely on perceptual data 
appears to be inadequate to detect differences between the fluent speech of stutterers and normal speakers. For this reason, acoustic data rather than perceptual identification of speech differences was used in the present study.

OBSERVED DIFFERENCES BETWEEN STUTTERED AND FLUENT SPEECH

Various studies have investigated whether significant differences exist between stutterers and fluent speakers relating to acoustic and Iinguistic variables.

\section{Acoustic Variables}

Various acoustic cues have been associated with the stuttering moment. Variables such as fundamental frequency (Fo), (Falck, Lawler \& Yanovitz, 1985; Sacco \& Metz, 1989) number of pauses (Howell \& Wingfield, 1990; Love \& Jeffress, 1971; Viswanath, 1989; Williams, 1957), durations of words (Klouda \& Cooper, 1987; Prins \& Hubbard, 1990; Starkweather \& Myers, 1979; Viswanath, 1989), and speech rate (Howell \& Wingfield, 1990) will be discussed here as they relate to the acoustic signal.

\section{Fundamental frequency.}

Falck et al. (1985) found changes in fundamental frequency in the 1,024 $\mathrm{msec}$ time frame prior to a stuttering moment. Mean fundamental frequency was consistently lower during each quarter segment (1-256 $\mathrm{msec}, 257-512 \mathrm{msec}, 513-$ $768 \mathrm{msec}$, and 769-1024 $\mathrm{msec}$ ) in prestuttered compared with 
prefluent utterances. If vicinity effects were observed to occur in fundamental frequency, there is a possibility that word durations may also be affected. Sacco and Metz (1986, 1989) investigated the abilities of stutterers and controls to achieve and maintain a consistent $F_{0}$ over repeated utterances. Words consisting of vowels joining initial voiced and voiceless stop consonants (pet, pat, pig, bet, bat, big) embedded in short sentences were used. Words were digitized, displayed and expanded on a graphics terminal. A waveform editor was used to determine $F_{0}$ of vowels following the initial stop consonant, approximately $100 \mathrm{~ms}$. into voice onset. No significance difference in Fo was found in the 1989 study. However, significantly more variability was documented in the 1986 analysis of the same data. Only Eluently produced words were examined in both studies. However, in the 1986 study, stutterings in the immediate vicinity of examined words were ignored. In the second study, if any word in the carrier phrase was stuttered, the word targeted for examination in that phrase was disqualified. As a result of that change, 49 words were eliminated from the 1989 data corpus. They concluded: "the data strongly suggests the reality and importance of what one might call the 'spread' or 'vicinity' effect of stuttering on adjacent fluently produced words. That is, discrete, overt stutterings seem to alter certain characteristics of perceptually fluent words that are in 
close proximity to the actual stuttering. The present data, when considered in light of the sacco and Metz (1986) data suggest that overt stutterings can influence the relative $F_{0}$ of vowels in the immediate vicinity of the stuttering ( $p$. $443) \cdot "$

Sacco and Metz (1989) also cited the importance of further detailed analysis of the effects of the stuttered word on surrounding speech and acknowledged the topic a profitable and key area of inquiry for future research. They stated, "A precise delineation of the nature and extent of the contaminating effects of stutterings on surrounding words could dramatically influence research efforts in this area (p. 443)." Given their findings of influence of the spread effect on vowel frequency, research of the effects on word duration would appear to be a valid question as well.

\section{Pauses.}

Love and Jeffress (1971) found that stutterers exhibit significantly more pauses in their utterances than nonstutterers. Twenty-five normal speakers with no prior history of speech problems matched (for sex and age) with 25 stutterers ranging in age from 11 to 42 were audiotaped on four oral reading samples each. The 50 speech samples were then amplified and processed using a Computer of Average Transients (CAT) as the basic unit. Time gradations identified with the computer addresses of the CAT were calibrated with a pulse generator such that each pause 
counted in a separate CAT address indicating its length. Address contents were printed out and transcribed after each reading. Time segment frequencies for readings of normal speakers and stutterers were converted into 25th, 50th, 75 th, and 90 th percentiles to compare length of pause durations for the two groups. The stuttering group had significantly more pauses 150 to $250 \mathrm{msec}$ long with the $50 \mathrm{th}, 75 \mathrm{th}$, and $90 \mathrm{th}$ percentiles containing the largest differences. The smaller difference in the means at the 25 th percentile level may indicate that fluent speakers spend similar amounts of pause time required for phonation of the same sounds as do stutterers. A very simple SpeechPause Counter was then used to verify the number of pauses longer than the $150 \mathrm{msec}$ criterion identified with CAT instrumentation. The counter contained a simple relay switch mechanism which remained open as long as speech sounds were incoming, and closed (advancing the counter) when a pause longer than $150 \mathrm{msec}$ occurred. All 50 tapes were re-analyzed and the same difference between the two groups was verified. The perceptual judgments of a speech/language pathologist were then compared to instrumentation data resulting in 568 overall correct identification. When stutterers' speech exhibited exaggerated pause lengths, less decision time was required to make the judgment. However, when the number of pauses between normal and stuttering speakers approached median 
frequency, the clinician took longer to make the decision and did so with less accuracy. The greater number of brief pauses identified with stutterers in this study lends support to Williams' (1957) belief, as noted earlier, that the speech of stutterers differs from the norm, even in their fluent utterances.

Howell and Wingfield used acoustic data from their digital recordings to compare duration, rate, number of pauses, and mean intensity between fluent and stuttered speech segments. Significant differences were found in intensity drop between the syllables in experimental (stuttered) and control (fluent) sections (intensity peaks were longer in stuttered than in fluent sections). No differences were observed, however, in duration, rate, number of pauses or average intensity between the sections. The influence of sample context must be noted here as a variable. Comparisons in this study were not between exact word pairs. Howell and Wingfield compared non-identical clauses.

Viswanath (1989) compared total articulation time (TAT) and total pause time (TPT) between stutterers (SD, stutterer dysfluent; SF, stutterer fluent) and control subjects (CD, control dysfluent; CF, control fluent). Between the first two readings, stutterers (SF) displayed a sharp drop in TPT compared to the more gradual decrease of fluent subjects $(C F)$. He concluded that "longer duration of words (as 
reflected by longer TAT), longer, and/or more frequent pauses (as reflected by TPT) are likely to be associated with a stuttering event (p. 261)." He hypothesized that if the planning process actually imposes a constraint on the duration of an utterance, then asymmetrical buildup and build-down to and away from a stuttered moment would be expected (ie. longer word durations prior to a stutter might be balanced by shorter durations following the episode). Viswanath's data evidenced buildup to the stuttered moment. Increased differences were observed between stutterers and controls in successive locations approaching an episode, in positions $\mathrm{x}-2$ to $\mathrm{x}-1$ to $\mathrm{x}(\mathrm{x}-2$ refers to the word occupying the position two words prior to the stuttered word; $\mathrm{x}-1$, one word before the stutter; $\mathrm{x}$ being the stuttered word). However, moving away from the stuttered moment, the process reversed in the $x+2$ location, confusing the symmetry profile. It was concluded that data was insufficient to document if a stutterer "gradually slows down by increasing the frequency and duration of pauses before a stuttering event and does the opposite after it (p. 263)." Viswanath called for a replication of his study using a larger, more controlled sample of utterances to more precisely determine if increase in pause time before a stutter with a decrease following its occurrence can be accounted for by lexical (word characteristics) or linguistic (word position within the clause) variables. No mention was made as to whether 
treated subjects were used in the study or if the treatment variable was controlled.

In marked contrast, Howell and Wingfield (1990) found no significant difference in pauses (or in duration, rate, or average intensity) between stutterers and controls. Significant differences were observed, though, in the length of adjacent dips and peaks in the intensity-time profile between groups. Since both acoustic and perceptual methods were used in gathering, recording and analyzing their data, it was concluded that the stuttered moment affects the intensity-time component in areas adjacent to the episode such that perceptual judgment cues are sufficient to reliably judge the presence and type of stutter (listeners were unable, however, to accurately judge position of the episode)

\section{Durations.}

In the Viswanath study (1989), which captured timing effects within the context of clausal utterances, data indicated that stutterers tend to lengthen the word preceding the stuttered moment. It is proposed that a significant increase in duration accounts for the eventual fluent production of a word over repeated readings in an adaptation process. The greatest tendency to increase the duration of the stuttered word was observed to occur between the first and second readings with changes in duration 
ceasing to exist one position removed from the stuttering episode. Duration increases in the second reading occurred despite a 2 minute pause permitted between tasks as part of the procedure. Conversely, with control subjects, duration decreased between the first and second readings, increased between the second and third, then stabilized throughout the remaining readings. Significantly longer durations for words in location $x_{p}$ (the last word of the clause before the disruption) were noted compared to normal speakers in all five readings. The increase of duration in the last word of the clause preceding the stuttered word may indicate anticipatory evidence that speakers have some foreknowledge that they are going to slip. Postma and Kolk (1994) refer to this foreknowledge as "prearticulatory editing", or the stutterer's ability to detect errors prior to overt production. The proposal that stuttering diminishes as amount of planning time for utterances increases (Perkins, Bell, Johnson \& Stocks, 1979) appears to support the prearticulatory editing explanation of longer $x_{p}$ durations prior to the stuttered word.

\section{Rate.}

Based on the differences between experimental and control sections approaching significance in their speech rate data, Howell and Wingfield (1990) suggest that rate may play a minor part in a listener's ability to discriminate between utterance segments adjacent to a stutter and those 
more distant. Correlations between the other acoustic measures (duration, number of pauses, and average intensity) and listener judgments were not significant, except for speech rate.

Howell and Wingfield disclose the fact that several of their subjects had been treated unsuccessfully with various therapies prior to the study. Viswanath gives no information regarding treatment history of his participants. The treatment variable, not surprisingly, has an effect on speech rate. Treatment has been found to result in longer voice onset time (Shenker \& Finn, 1985) and longer vowel durations (Metz, Samar \& Sacco, 1983), each having its impact on speech rate. For this reason, holding the treatment variable constant in research investigations appears to be of value.

\section{Linquistic Variables}

The location of stuttering within an utterance may be affected by linguistic factors. The operation of semantic, syntactic, prosodic, and phonological elements have been demonstrated to impact fluency.

\section{Semantic factors}

Correlation has been shown to exist between the frequency or conspicuousness of words and stuttering severity (Danzger \& Halpern, 1973; Hubbard \& Prins, 1994; Trotter, 1956). Schlesinger, Forte, Fried, \& Melkman 
(1965), in a Hebrew study, noted the interaction effect of frequency and predictability. Words high in frequency but low in predictability tended to increase stuttering. Frequent, predictable words were least stuttered. Conversely, the combination of low frequency and low predictability words were most likely to be stuttered. Syntactic factors

Syntactic complexity of an utterance also appears to elevate stuttering rates (Wells, 1979). Brown (1938) advocated that stuttering usually occurred on the first three words of a clause. Conversely, Kassin and Bjerkan (1982) suggested that stuttering occurs on words critical to the message. Since critical words fall in final positions in sentences, they propose that stuttering tends to occur at the ends of utterances, not at the beginning. Klouda and Cooper (1987) found that normal speakers, as well as stutterers, lengthen words that occur in clause-final position and are more apt to place a pause after a word preceding a major syntactic boundary. In a perceptual study, they were unable to find any evidence that the existence of a major syntactic boundary contributed to an increase in stuttering frequency.

\section{Prosodic factors}

Blankenship's (1964) report of more pauses and stutters associated with content as opposed to function words lends support to grammatical theories. According to wingate 
(1988), however, linguistic stress can account for the tendency of stuttering to occur on sentence initial versus sentence final words, low versus high frequency words, long versus short words (poly-versus mono-syllabic words)(Wingate, 1967; Silverman and Williams, 1967), and the content versus function feature noted by Blankenship.

It is Wingate's contention that prosodic features actually determine what is thought to be the operation of grammatical factors and that linguistic stress is central to stuttering. He states that stuttering represents "a lack of proper synchrony of Iinguistic elements in terms of utterance planning (p. 266)." He suggests that timing errors occur within words (retrieving the word and sequencing its sounds) as well as between words (assembling the utterance) in running speech.

\section{Phonological factors}

The possibility that stuttering results from the complexity of phonatory coordinations with articulation and respiration was strongly supported by Perkins, Rudas, Johnson, and Bell (1976). Speech sounds are produced in a highly context-dependent manner. The physical features of coarticulated phonemes are mixed with and dependent upon sounds which precede and follow. This noted, one concern of the present study was to systematically exercise all potential combinations of phoneme-related stuttering occurrences, including lingual and labial postures that, 
historically, tend to trigger disruption (stops, plosives, etc.).

Adams and Reis (1971) suggest that stuttering occurs more frequently when the speaker must shift back and forth between voiced and voiceless productions. The effect becomes compounded if the words occur at clause boundaries or stress points. In their study, all-voiced passages were produced more fluently than those loaded with off-on voicing requirements. To ensure fluent movement from voiced (/b/, $/ \mathrm{d} /, \mathrm{g} / \mathrm{,} / \mathrm{v} /$, etc., and all vowels) to voiceless $(/ \mathrm{p} /, / \mathrm{t} / \mathrm{l}$ $/ \mathrm{k} /, \mathrm{f} /$, etc.) productions, Ham (1986) advises use of prolongation and light articulatory contact paired with easy onset (as opposed to hard glottal attack).

stuttering occurs more frequently on consonants than on vowels (St. Louis, 1979). The recurrence of phonetic context also has marked effects on speech error rates (Dell, 1984). In other words, stuttering increases when the same phoneme appears in a similar phonetic context shortly before or after the disruption. These factors appear to indicate that the phonological encoding processes may be faulty in people who stutter.

If the first sound of a syllable is produced, restart from the syllable beginning will lead either to a sound repetition or to a sound prolongation. The latter, of course, is possible only if it is a continuable phoneme. Whether a prolongation or a repetition surfaces may depend 
on how far the phoneme is completed at the moment of interruption. Berg (1986) reports that in overt withinword self-repairs, interruption occurs usually after the vowel and at syllable boundaries. A treatment hierarchy of phonemic difficulty is recommended (Ham, 1990), moving from unvoiced and voiced continuant combinations (ie. sun, nice), to plosives (ie. pie, boy), and all voiced continuants (ie. man, zone), to the more difficult plosive-stop combinations (ie. bit, pod), the latter requiring maximum attention to light contact, easy onset, and continuous movement to maintain fluency. Such a hierarchy appears to imply that there is a shared underlying component in stuttering that causes phonological encoding problems during planned speech. For the present study, oral reading was selected to enable control of confounding linguistic factors while measuring the effects of stuttering on word durations immediately preceding and following the stuttered word. Semantic, syntactic, prosodic, and phonological elements were controlled in that both subjects read the same 83 phonetically balanced sentences. Where reading errors occurred (altering linguistic content), stuttered samples were excluded from the data corpus. The linguistic variable of word position was controlled by eliminating analysis of all stuttered words occurring in clause-initial or -final positions. A continuum of both long and short sentences was used ranging from 4 to 15 words with combinations of mono- 
and poly-syllabic words. The sentences were specially designed to be phonetically balanced (vowels, consonants, and blends were systematically paired).

Each phoneme was represented in initial, medial, and final word positions to rule out fluency errors avoided or caused by the phonological encoding difficulties cited by wingate (1988) as a source factor for stutter events.

\section{RATIONALE FOR ACOUSTIC INVESTIGATION}

Speech usually involves strings of sounds uttered in rapid succession. In running speech, the individual sounds can lose some of their distinctiveness. Coarticulation, the phenomenon in speech in which the attributes of successive speech units overlap in articulatory or acoustic patterns, renders listener perception of word boundaries an extremely difficult task. Articulation takes time, so speech sounds begin and end gradually. Onset and offset of voicing represents a continuum, the initial and terminating portions of which are not easily detected by the human ear. Read, Buder \& Kent (1990) report that A/D (analog to digital) converters are limited to about 25,000 samples per second on a PC-AT while others are capable of running at twice that rate. The instrumentation utilized in our study ran at 40,000 samples per second. The obvious advantage of using 
acoustic instrumentation capable of such high sampling rates to examine the speech signal is that of precision.

The best listener agreement for one of the most recent perceptual studies (Cordes, Ingham, Frank \& Ingham, 1992) failed to exceed the 608 level for even experienced judges. To investigate the spread effects of stuttering on adjacent words, there is a need for valid, reliable measurement techniques. Gross determination of whether or not a stutter occurred are more suited to perceptual investigation than measuring the effects of a neighboring stutter on words one word removed from the moment of stuttering. The advantages of acoustic analysis include the capabilities of storing the speech signal, displaying it as an oscillographic trace, performing and recording mathematic calculations of exact word durations. These advantages promote the capture of extremely accurate data.

In this chapter, literature pertaining to the moment of stuttering was reviewed, findings from studies based on listener judgments were presented, observed differences between stuttered and fluent speech were discussed in terms of acoustic and linguistic variables, and finally, a rationale for acoustic investigation to detect evidence prior to and following the moment of stuttering was given. Further empirical data in the form of group and single subject research designs are needed to accumulate a wider base documenting the duration effects stuttering has on 
surrounding speech. To the extent that the variables of treatment and context can be controlled, additional confidence in results, for purposes of theory construction, may result.

The goal of the present study, therefore, was to maximize confidence in results by: a) comparing only identical clauses to control for context variables, b) excluding clause-initial and -final samples to control linguistic variables, c) requiring subjects to have no prior treatment (or a three year minimum since last treatment) to control for treatment variables, d) minimizing the adaptation effect by having only two readings with a 30 minute rest period between readings, e) maximizing agreement on stuttering samples selected for analysis by requiring unanimous agreement among judges for inclusion in the data corpus, and f) using acoustic equipment with 40,000 sampling rates per second to promote accuracy . 
CHAPTER III

METHODS AND PROCEDURES

\section{INTRODUCTION}

Between the months of October 1991 and October 1992 at the Florida State Speech and Hearing Sciences Clinic, subjects ranging in age from 20 to 35 years, were administered the Stuttering severity Instrument (SSI) (Riley, 1983) by John Tetnowski, speech-language pathologist and doctoral candidate. This investigator chose two of the original nine subjects to be utilized in this present study.

\section{SUBJECTS}

\section{Original study}

Six subjects from the Florida State Speech and Hearing Sciences Clinic ranging in age from 20 to 35 years served as subjects for the original 1992 study (Tetnowski and Morris, 1991). Each of the subjects met certain selection criteria for the original study. These criteria included:

1. No prior treatment for stuttering or no treatment for at least three years prior to participation. 
2. Minimal severity of "moderate" as scored on the SSI.

3. No apparent disorder of speech, hearing, or language, except for stuttering.

\section{Present Study}

Reel-to-reel audio-tapes of two adult male subjects, recorded by the investigator of the original study (in addition to those of the six subjects) were randomly selected for the present study. Both subjects met the above selection criteria and had been audio-taped using the same recording procedures.

\section{RECORDING PROCEDURES}

Each subject had been prerecorded sitting in a soundtreated room 20 centimeters from a shure model SM7 microphone, connected to an Ampex 301 reel to reel tape recorder reading the series of 83 sentences twice. A 30 minute rest period between the two readings was observed.

\section{STIMULUS MATERIALS}

Oral reading was designed to enable control of confounding linguistic factors while measuring durational "spread" effects of the stuttered word. Eighty-three sentences (Fairbanks, 1960) provided a common pool of target words for subsequent acoustic analysis (Appendix A). The 
sentences were specially designed to be phonetically balanced.

Each phoneme was represented in initial, medial, and final word positions to rule out fluency errors avoided or caused by the phonological encoding difficulties cited by Wingate (1988) as a source factor for stutter events. For example, the /s/ phoneme was presented in the following positions: "Some people (initial), "frequently deceived" (medial), and "his lips" (final). The consonant environment of each representative phoneme was also systematically varied. For example, the /i/ phoneme in the first two sentences was varied according to the following consonant parameters :

$\begin{array}{lll} & \text { after } & \text { before } \\ \text { people } & / \mathrm{p} / & / \mathrm{p} / \\ \text { reason } & / \mathrm{r} / & / \mathrm{z} / \\ \text { seeing } & / \mathrm{s} / & / \mathrm{I} / \\ \text { believing } & / \mathrm{b} / & / \mathrm{l} / \\ & / \mathrm{l} / & / \mathrm{v} / \\ \text { feel } & / \mathrm{f} / & / \mathrm{l} / \\ \text { frequently } & / \mathrm{fr} / & / \mathrm{kw} / \\ \text { deceived } & / \mathrm{d} / & / \mathrm{s} /\end{array}$

Each of the 83 sentences was read twice by each subject. Instructions were, "Please read the sentences at a 
rate and loudness level that is comfortable to you." No other instructions were given.

\section{IDENTIFICATION OF STUTTERING MOMENTS}

Three judges (two second year graduate Speech-Language Pathology students and one certified Speech-Language Pathologist supervisor with extensive experience in stuttering disorders) created a data corpus by listening to all 83 sentences and identifying each moment of stuttering. Stuttering instances were judged to occur according to the rules established in the Riley Stuttering Severity Instrument (SSI) (Riley \& Riley, 1983) definition of stuttering behaviors.

Repetitions or prolongations of sounds or syllables (including silent prolongations) were considered stuttering. Rephrasing, tense pauses, and repeating words of more than one syllable were not counted as stuttering. Inclusion of data in the corpus for subsequent analysis was dependent upon unanimous agreement among all three judges. Criteria for inclusion in the data corpus were words that were stuttered during one of the readings but not the other. Criteria for exclusion from this list were three additional constraints :

1. Any stuttered word occurring at the beginning or end of a sentence or syntactic unit 
2. Any stuttered word immediately preceding or following an episode of stuttering which occurred at the beginning of a sentence or syntactic unit

3. Any stuttered word occurring immediately before or following another stuttered word

\section{READING ERRORS}

Errors in reading were determined for each subject by comparing the recorded spoken utterances with the sentence texts. Any sentence on which an error occurred was excluded from analysis. Dropping words and word endings, substituting one word for another, and dropping or changing the phonetic elements of a word were all considered reading errors. No single subject made more than 5 reading errors during the 83 sentence task.

\section{EXCLUDED DATA}

The data corpus for speaker NM had 40 of 67 stuttered words excluded for not meeting criteria due to location of the stuttered word or occurrence of a reading error. The data corpus for speaker DS had 9 words excluded from the original 22 stuttered words. Words qualifying for acoustic analysis totaled 27 from Speaker NM and 13 from Speaker DS. A combined total of 40 words were analyzed. 


\section{ACOUSTIC ANALYSIS PROCEDURES}

The data acquisition system used and supported by Canadian Speech Research Environment (CSRE) was a TuckerDavis Technologies System II (AT\&T DSP-32 based) configuration. The signal was digitized through a 2 Channel, 16 bit A/D and D/A board to a Gateway 2000 Local Bus Computer System with an 80486 processor. Components of the System II hardware configuration included:

\section{TABLE I \\ COMPONENTS INCLUDED IN THE CONFIGURATION OF THE SYSTEM II HARDWARE}

AP2 $50 \mathrm{MHz}$ Array Processor w/Optical Interface

DD1 2 Channel, 16 bit $A / D$ and $D / A$

PA4 Programmable Attenuator

P12 Enhanced Parallel Interface Adapter Module

HB5 Stereo Headphone Buffer/Driver

MS1 Monitor Speaker with Two Watt Amplifier

MA1 Microphone Amplifier with LED meter

XB1 Quad Device Caddie

OI1 XBUS--Optical Interface

PWS25 25 Watt Rack-Mount Power Supply

Figure 1 illustrates the configuration of the system II hardware. The speech signal was delivered via reel to reel tape recording input to the amplifier, filter, and XBUS Interface to the Gateway $2000 \mathrm{PC}$ on which the spectrogram was displayed and analyzed. 


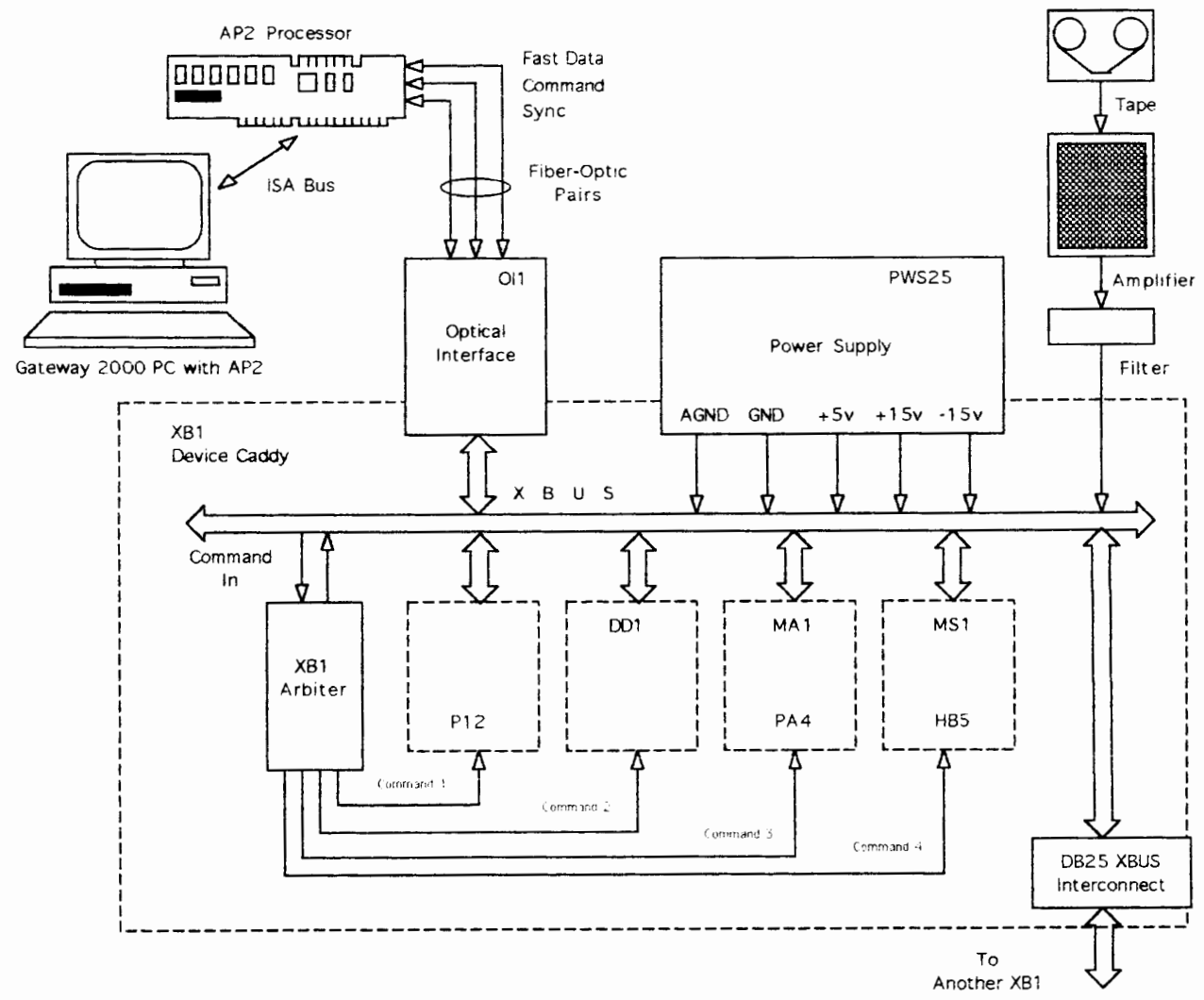

Figure 1. Diagram illustrating the configuration of the system II hardware. 
Time analysis was performed on the selected words occurring immediately before and after a stuttered moment in each stuttered speech sample and its matched fluent counterpart. The CSRE program was used to perform duration analysis of the speech signal, displaying the sentences as oscillographic traces. Using auditory and visual cues, the target words were identified and packeted into triplet units, with the target word occupying the middle position. This was done to insure that all onset and offset portions of target word waveforms were indeed captured for analysis. Each three word packet was then saved to disk for later analysis.

In the analysis procedure, onset and offset of voiced target words was determined by zooming in, editing and marking the first and last negative peak of the quasiperiodic vocal wave. For voiceless sounds, the point at which the amplitude doubled or halved from the level of background noise defined onset and offset locations. By moving the cursors to these locations and playing back the sound between them, it was determined if the entire word had been marked without omitting any sounds or including adjacent ones. With the end points determined, the CSRE program then calculated the duration of the selected word in msec. and displayed it on the screen. 
REIIABIIITY

Speech samples for each of the two subjects were assigned 7 digit alpha-numeric filenames. For example, the number NM02041 indicated (in reverse order) that the word was from the first reading (1), the fourth word (04), in the second sentence (02) from the sample of the specified subject (NM). A minimum of two iterations of the duration calculation were performed on each alpha-numeric word file for intra-judge reliability. Scores were then correlated with a second judge who performed duration calculations on 108 of the data (Hall \& Yairi, 1992).

Duration measurements were grouped according to the following categories: 1) duration of the word occurring immediately before the stuttered moment (BSTUT); 2) duration of the same word fluently produced from the corresponding nonstuttered sample (BNSTUT); 3) duration of the word occurring immediately after the stuttered moment (ASTUT); and 4) duration of the same word fluently produced from the corresponding nonstuttered sample (ANSTUT). These msec duration measurements were then subjected to two-tailed ttests pairing the two matched samples (BSTUT with BNSTUT; ASTUT with ANSTUT). 
CHAPTER IV

RESULTS AND DISCUSSION

\section{DESCRIPTIVE DATA}

The purpose of this study was to determine if acoustic evidence exists to support the concept that words before and after a stuttered word are different from those produced by the same speaker, in the same context, in a fluent speech sample. Specifically, word durations immediately before and after the stuttered word were examined.

\section{Duration Analysis}

Words that were stuttered during one of the readings but not the other were considered for inclusion in the data corpus. Criteria for exclusion from this list included words which:

1) occurred at the beginning or end of a sentence or syntactic unit, 2) immediately preceded or followed a stuttered word which occurred at the beginning of a sentence or syntactic unit, or 3 ) occurred immediately before or following another stuttered word.

Words preceding (BSTUT) and following (ASTUT) the stuttered words together with their nonstuttered 
counterparts (BNSTUT and ANSTUT) were then identified and analyzed to determine durations in msec. The data corpus for the two subjects are listed respectively in Appendices $B$ and $\mathrm{C}$.

One sample, two-tailed t-tests were then completed to determine if a significant difference existed between words preceding (BSTUT vs. BNSTUT) and following (ASTUT vs. ANSTUT) words that were stuttered in one sample but were produced fluently in the corresponding match. The level of confidence was set at .05 .

The t-test results for both subjects combined showed a significant difference $(\mathrm{p}=.0043)$ between msec. durations comparing BSTUT vs. BNSTUT (See Table II). This analysis indicated that the mean duration of words immediately preceding the stuttered word (BSTUT) was significantly different than that of the corresponding fluent sample (BNSTUT) •

\section{TABLE II}

RESULTS OF A T-TEST COMPARING WORD DURATION DIFFERENCES IN POSITIONS BEFORE A STUTTERED WORD WITH THOSE OCCURRING BEFORE A NON-STUTTERED WORD

\section{$\underline{N}$ MEAN STDEV SEMEAN $\underline{\text { I }} \underline{\text { VALUE }}$}

Combined $40 \quad 50.5 \quad 105.2 \quad 16.6 \quad 3.03 \quad 0.0043$ * Results

*Alpha level was significant at $\mathrm{P}<.05$ 
With combined analysis of both subjects $(N=40)$, durations of words occurring immediately before the stuttered word averaged $50.5 \mathrm{~ms}$. differences in duration than those measured before the non-stuttered word in the matched sample.

Significant differences were also found to exist between ASTUT vs. ANSTUT. This analysis indicated that the mean duration of words immediately following the stuttered word (ASTUT) was significantly different than that of the corresponding fluent sample (ANSTUT).

TABLE III

RESULTS OF A T-TEST COMPARING WORD DURATION DIFFERENCES IN POSITIONS AFTER A STUTTERED WORD WITH THOSE OCCURRING AFTER A NON-STUTTERED WORD

$\underline{N}$ MEAN STDEV SE MEAN $\underline{\text { S }}$ VALUE

Combined $40 \quad 23.5 \quad 59.0 \quad 9.3 \quad 2.51 \quad 0.016$ *
Results

*Alpha level was significant at $\mathrm{P}<.05$

With combined analysis of both subjects $(N=40)$, durations of words occurring immediately after the stuttered word averaged $23.5 \mathrm{~ms}$. differences in duration than those measured after the non-stuttered word in the matched sample. A p-value of 0.016 revealed a significant difference in word durations immediately following a stuttered word compared with durations in the corresponding fluent sample at the .05 level of confidence. 
The overall data obtained during this investigation revealed that there were significant differences between word durations both before and following a stuttered word compared to word durations of the exact counterparts from a non-stuttered sample. These data are similar to Viswanath's (1989) whose findings indicated that stutterers lengthen the word preceding a stuttering event. His data examining word durations immediately before the stuttered word, however, approached, but did not reach significance $(p=.07)$. Results comparing durations following the stuttered word ( $p$ $=0.21$ ) indicated "that statistically significant carryover effects do not exist in the words immediately following the stuttered word (p. 259)." It should be noted that Viswanath examined six word positions rather than just the two positions examined in this study. While no reliability data was included in the Viswanath study, investigator's calculations of word durations in the present study were compared to those of a reliability judge. Our results appear to indicate that the stuttered word influences durations of words immediately surrounding its occurrence ( $50.5 \mathrm{~ms}$. mean differences before compared to $23.5 \mathrm{~ms}$. mean differences in duration after the stuttered word) • 
$\underline{\text { Reliability }}$

In order to determine the degree of relationship between the examiner's duration calculations and those of the reliability judge, a Pearson $r$ product-moment was computed. Perfect agreement would be indicated by a 1.0 correlation. The concern is not so much with agreement as with consistency as measured by the correlation between the two scoring performances. Although calculations were not in exact agreement (the investigator's calculations of durations were consistently and predictably shorter than those of the reliability judge), strong correlations were found to exist between the judge's scoring and that of the examiner $(r=.961)$. This high correlation indicates a close association, or a high index of relationship, between the scoring of the two examiners. The amount of shared variance between the examiner and judge was determined by calculating $\mathrm{r}^{2}$. The shared variance was high, at $92 \%$.

\section{DISCUSSION}

In interpreting the findings of this study in relation to past knowledge, it is noted that Viswanath (1989) called for a replication of his study using a larger, more controlled sample of utterances to rule out the effects of lexical or linguistic variables. The present study is certainly not a replication of that study (Viswanath analyzed adaptation effects and pause time in addition to 
articulation time). However, in examining word durations specifically, a larger, more controlled sample was used in the present study.

Reading material in the Viswanath study consisted of two Thurber short stories. The pre-existing prose had been crafted for amusement rather than in an attempt to sample systematically the various phonemes. The present study used 83 phonetically balanced sentences written specifically to represent the controlled sample referred to by Viswanath. The 1989 study isolated only 8 stuttered words, compared to 40 words in the data corpus of the present study. The latter data corpus represents a larger sample.

Viswanath examined durations of words in 7 clausal locations: $\mathrm{xp}$ (last word of the previous clause), $\mathrm{x}-2$ (2 words before the stuttered word), $\mathrm{x}-1$ (the word immediately preceding the stuttered word), $\mathrm{x}$ (the stuttered word), $\mathrm{x}+1$ (the word immediately following the stuttered word), $\mathrm{x}+2$ (2 words after the stuttered word), and $\mathrm{x}_{f}$ (the first word of the clause following that of the stuttered word). The present study represents a more targeted focus in that durations of words only immediately preceding and following the stutter were examined. Viswanath encouraged and examined adaptation effects over five readings by imposing only a two minute pause between readings. It has been suggested that the reason stuttering is significantly less when the speaker reads aloud is that it permits practice in 
coordinating phonatory with articulatory movements (Brenner, Perkins, and Soderberg, 1972). The present study controlled for adaptation effects by including only two readings separated by a mandatory 30 minute interim.

In the present study, comparisons were made of the same word uttered by the same speaker in both fluent and stuttered samples. Viswanath's study compared exact words represented in the same clausal utterances (fluent and stuttered), but utilized matched normal speakers for the non-stuttered sample.

The investigator realizes the limitations of the methods used to collect the preceding data. At any given time the acoustic signal contains information about several sound segments. The physical features of any particular phone are mixed with and dependent upon those which precede and follow it. Speech sounds are not as separate as they seem, they overlap and mix with adjacent sounds. The mechanism does not complete production of one sound before it begins production of the next. Lip rounding and velar opening are usually initiated several segments before they are required and continue several segments after. For example, within-word coarticulation occurs in the sentence, "John started toward the barn." Lip rounding is accomplished mid-word with the /o/ and is coarticulated transitioning to the $/ w /$ whose required lip rounding has already been achieved. How much of the homogeneous speech 
signal is to be assigned to the vowel, and what portion to the glide? A related example of between-word coarticulation on the same sound occurs in the sentence, "The tornado was not far distant." The same lip rounding coarticulation crosses word boundaries. Depending on the speaker's rate, coarticulation may involve similar duration times betweenas within-words.

Elimination of the stress variable from subjects' readings by indicating common stress points may have prevented errors based on differences in rhythm and prosody imposed by arbitrary stress patterns which were determined by each subject. Results of several studies indicate that stuttering occurs more often on stressed syllables (Bergmann, 1986; Prins, Hubbard \& Krause, 1991; Wingate, 1988).

Suggestions for future research would include using the same techniques and controls to examine additional word positions (for example, $\mathrm{x}+/-2, \mathrm{x}+/-3, \mathrm{x}_{p}$, and $\mathrm{x}_{f}$ ). More spontaneous stimulus material (not reading), such as action picture identification, would provide useful information and an even larger sample. 
CHAPTER V

SUMMARY AND IMPLICATIONS

\section{SUMMARY}

The literature supports opposing views as to whether stuttering is confined to a singular instant of disruption in fluent speech, a stuttered "moment", or that it rather represents a continuum of fluent to nonfluent speech. The latter view proposes a "spread" effect throughout the utterance suggesting that measurable changes occur in this continuum of the speech signal between fluent and nonfluent output.

The purpose of the present study was to determine if differences, specifically in word durations, existed in the vicinity of the stuttered word. Word durations were examined immediately preceding and following the stuttered word and compared to the exact word of a corresponding fluent sample from the same speaker. Two subjects were selected, each of whom 1) had been assessed as a moderate to severe stutterer, 2) had no major speech or language disorders, and 3) had either never received treatment for 
stuttering or had not received treatment for a minimum of three years.

Both subjects read 83 phonetically balanced sentences twice with an imposed 30 minute break between readings to minimize the affects of adaptation. Words were selected into the data corpus that had been stuttered in one of the readings but not the other. From this list, words were then eliminated which 1) occurred at the beginning or end of a sentence or syntactic unit, 2) directly preceded or followed an episode of stuttering, or 3) were misread, in which case, any previously qualifying word from the entire sentence was eliminated from the data corpus.

Analysis consisted of spectrographic measurement of word durations in positions prior to and following the instance of stuttering and comparing those durations with those of the exact corresponding words from the nonstuttered sample. One sample, two-tailed t-tests were then completed to determine if a significant difference existed between words preceding (BSTUT vs. BNSTUT) and following (ASTUT vs. ANSTUT) words that were stuttered in one sample which were produced fluently in the corresponding match. Significance was set at the .05 level of confidence. Results indicated significant differences in word durations in both positions, before $(p=.0043)$ and after $(p=.016)$ the stuttered word compared with durations of the non-stuttered counterpart. More significant differences in word durations were found in 
the word position prior to the stutter (mean difference between stuttered and non-stuttered words averaged 50.5 msec.) compared to differences following the stutter (mean difference between stuttered and nonstuttered words averaged $23.5 \mathrm{msec})$. Findings support the contention that stuttering is a disorder of timing and provide additional acoustic evidence of the spread effect on word durations immediately before and following the stuttered moment.

\section{IMPLICATIONS}

Research Implications

The results of this study, although significant, indicate the need for further research on acoustic evidence of the spread effect on word durations surrounding the stuttered moment. The findings of one study are in need of additional support to establish or corroborate theory. Where knowledge about a topic can only be provided by a series of studies, specific suggestions regarding further research are of the greatest importance. Indicating common stress points in the stimulus material would eliminate the stress variable which was not controlled in this study. Use of same-word, same-speaker comparisons insures validity of differences found (Armson \& Kalinowski, 1994), and large samples enhance control for lexical and linguistic variables. 
Defining what is a "large" sample is relative. Viswanath used two short stories totalling 740 words. The 83 phonetically balanced sentences in the present study comprised 711 words and netted 40 stuttered words passing exclusion criteria. It should be noted also that use of samples, however large, without systematic design for exercise of all phoneme combinations falls short of controlling for that variable.

\section{Clinical Implications}

The efficacy of timing therapies is based on the proposal that stuttering diminishes as the amount of planning time for phonetic voice-onset coordinations increases (Perkins, Bell, Johnson \& Stocks, 1979). Past research has demonstrated that when stutterers slow down the movement between, as well as within, sounds, relative to their own rate of utterance, that they become more fluent (Andrews, Howie, Dosza \& Guitar, 1982; Andrews, Guitar \& Howie, 1980). "Smooth" or "prolonged" speech programs which systematically modify phonation and thereby directly increase motor speech planning time have been shown to result in a reduction of stuttering (Ingham, Montgomery \& Ulliana, 1983).

Another method of increasing effective planning time is to increase predictability of voice onset and thus reduce the need for planning time required when onsets are 
unpredictable. During rhythmic stimulation, the stutterer's variability in time expansion is minimized between each adjacent syllable and in each syllable's vowel duration (Brayton and Conture, 1978). Use of the metronome or tapping can provide rhythm cues for the initiation of each speech segment.

If the foregoing is indeed true, then any clinical procedure that effectively generates more time to plan temporal speech coordination should enhance fluency. Data from the present study indicates different word durations immediately before and following the stuttered word. Therefore, it appears that evidence of different word durations before and after the stuttered moment would imply benefit from time "bought" by employing smooth speech techniques consistently throughout all utterances. 
REFERENCES

Adams, M. \& Reis, R. (1971). The influence of the onset of phonation on the frequency of stuttering. Journal of Speech and Hearing Research, 14, 639-644.

Andrews, G., Guitar, B., \& Howie, P. (1980). Meta-analysis of the effects of stuttering treatment. Journal of Speech and Hearing Disorders, 45, 287-307.

Andrews, G., Howie, P., Dosza, M., \& Guitar, B. (1982). Stuttering: Speech pattern characteristics under fluency- inducing conditions. Journal of Speech and Hearing Research, 25, 208-216.

Armson, J., \& Kalinowski, J. (1994). Interpreting results of the fluent speech paradigm in stuttering research: Difficulties in separating cause from effect. Journal of Speech and Hearing Research, 37, 69-82.

Berg, T. (1986). The aftermath of error occurrence: Psycholinguistic evidence from cut-offs. Lanquage and Communication, 6 , 195-213.

Bergmann, G. (1986). Studies in stuttering as a prosodic disturbance. Journal of Speech and Hearing Research, 29, 290-300.

Blankenship, J. (1964). Stuttering in normal speech. Journal of Speech and Hearing Research, 7, 95-96.

Brayton, E., \& Conture, E. (1978). Effects of noise and rhythmic stimulation on the speech of stutterers. Journal of Speech and Hearing Research, 21, 285-94.

Brenner, N., Perkins, W., \& Soderberg, G. (1972). The effect of rehearsal on frequency of stuttering. Journal of Speech and Hearing Research, 15, 483-486.

Brown, S. (1938). Stuttering with relation to word accent and word position. Journal of Abnormal and Social Psychology, 33, 112-120. 
Cordes, A.K., Ingham, R.J., Frank, P., \& Ingham, J.C. (1992). Time interval analysis of interjudge and intrajudge agreement for stuttering event judgments. Journal of Speech and Hearing Research, 35, 483-495.

Danzger, M., \& H. Halpern (1973). Relation of stuttering to word abstraction, part of speech, word length, and word frequency. Perceptual and Motor Skills, 37, 959-962.

Dell, G. S. (1984). Representation of serial order in speech: Evidence from the repeated phoneme effect in speech errors. Journal of Experimental Psychology: Learning, Memory, and Cognition, 10, 222-233.

Fairbanks, G. (1960). Voice and Articulation Drillbook. New York: Harper.

Falck, F. J., Lawler, P. S., \& Yanovitz, A. (1985). Effects of stuttering on fundamental frequency. Journal of Fluency Disorders, 10, 123-135.

Few, L. R., \& Lingwall, J. B. (1972). A further analysis of fluency within stuttered speech. Journal of Speech and Hearing Research, $15,356-363$.

Hall, K. D., \& Yairi, E. (1992). Fundamental frequency, jitter and shimmer in preschoolers who stutter. Journal of Speech and Hearing Research, 35, 1002-1008.

Ham, Richard. (1986). Techniques of Stuttering Therapy. Englewood Cliffs. New Jersey: Prentice-Hall.

Ham, Richard. (1990). Therapy of Stuttering: Preschool Through Adolescence. New Jersey: Prentice-Hall.

Howell, P. \& Wingfield, T. (1990). Perceptual and acoustic evidence for reduced fluency in the vicinity of stuttering episodes. Language and Speech, 33, 31-46.

Hubbard, C. \& Prins, C. (1994). Word familiarity, syllabic stress pattern, and stuttering. Journal of Speech and Hearing Research, $37,564-571$.

Ingham, R. J., Montgomery, J., \& Ulliana, L. (1983). The effect of manipulating phonation duration on $\mathbf{S}$ tuttering. Journal of Speech and Hearing Research, 26 , 579-587. 
Ingham, R. J. \& Packman, A. C. (1978). Perceptual assessment of normalcy of speech following stuttering therapy. Journal of Speech and Hearing Research, 21, 63-73.

Johnson, W. (1933). An interpretation of stuttering. Quarterly Journal of Speech, 19,70-77.

Kassin, K., \& Bjerkan, B. (1982). Critical words and the locus of stuttering in speech. Journal of Fluency Disorders, $7,433-446$.

Klouda, G. V., \& Cooper, W. E. (1987). Syntactic clause boundaries, speech timing, and stuttering frequency in adult stutterers. Language and Speech, 30, 263-276.

Love, L. R., \& Jeffress, L. A. (1971). Identification of brief pauses in the fluent speech of stutterers and nonstutterers. Journal of Speech and Hearing Research, 14, 229-240.

Metz, D. E., Samar, V. J., \& Sacco, P. R. (1983). Acoustic analysis of stutterers' fluent speech before and after therapy. Journal of Speech and Hearing Research, 26, $531-536$.

Metz, D. E., Schiavetti, N., \& Sacco, P. R. (1990). Acoustic and psychophysical dimensions of the perceived speech naturalness of nonstutterers and posttreatment stutterers. Journal of Speech and Hearing Disorders, 55, 516-525.

Perkins, W. H. (1983). The problem of definition: Commentary on stuttering. Journal of Speech and Hearing Disorders, $\underline{48}, 246-249$.

Perkins, W. H. (1984). Stuttering as a categorical event: Barking up the wrong tree - reply to Wingate. Journal of Speech and Hearing Disorders, 49, 431-433.

Perkins, W., Bell, J., Johnson, L., \& Stocks, J. (1979). Phone rate and the effective planning time hypothesis of stuttering. Journal of Speech and Hearing Research, 22, 747-755. 
Perkins, W., Rudas, J., Johnson, L., \& Bell, J. (1976). Stuttering: Discoordination of phonation with articulation and respiration, Journal of Speech and Hearing Research 19, 509-522.

Postma, A., \& Kolk, H. (1994). The covert repair hypothesis: Prearticulatory repair processes in normal and stuttered disfluencies. Journal of Speech and Hearing Research, 36, 472-487.

Prins, D., \& Hubbard, C. P. (1990). Acoustical durations of speech segments during stuttering adaptation. Journal of Speech and Hearing Research, 33, 494-504.

Prins, D., Hubbard, C.P., \& Krause, M. (1991). Syllabic stress and the occurrence of stuttering. Journal of Speech and Hearing Research, 34, 1011-1016.

Read, C., Buder, E., \& Kent, R. D. (1990). Speech analysis systems: A survey. Journal of Speech and Hearing Research, 33, 363-374.

Riley, G. D. (1983). Stuttering Severity Instrument. Tigard, Oregon, C. C. Publications.

Runyan, C. \& Adams, M. (1978). Perceptual study of the speech of "successfully therapeutized" stutterers. Journal of Fluency Disorders, $\underline{3}, 25-39$.

Runyan, C. \& Adams, M. (1979). Unsophisticated judges' perceptual evaluations of the speech of "successfully therapeutized" stutterers. Journal of Fluency Disorders, $\underline{4}, 29-38$.

Sacco, P. R., \& Metz, D. E. (1986, November), Fundamental frequency declination patterns in stutterers and nonstutterers. Paper presented at the meeting of the American Speech-Language-Hearing Association, Detroit, MI.

Sacco, P. R., \& Metz, D. E. (1989). Comparison of periodby-period fundamental frequency of stutterers and nonstutterers over repeated utterances. Journal of Speech and Hearing Research, 32, 439-444.

St. Louis, K. O. (1979). Linguistic and motor aspects of stuttering. Speech and Lanquage, 1, 89-210. 
Schlesinger, I. M., Forte, M., Fried, B., \& Melkman, R. (1965). Stuttering, information load, and response strength. Journal of Speech and Hearing Disorders, 30, $32-36$.

Shenker, R. C., \& Finn, P. (1985). An evaluation of effects of supplemental "fluency" training during maintenance. Journal of Eluency Disorders, 10, 257-267.

Silverman, E. M., \& Williams, D. E. (1967). A comparison of stuttering and nonstuttering children in terms of five measures of oral language development. Journal of Communication Disorders, 1, 305-309.

Starkweather, C. W., \& Myers, M. (1979). Duration of subsegments within the intervocalic interval in stutterers and nonstutterers. Journal of Fluency Disorders, 4 , 205-214.

Tetnowski, J. A., \& Morris, R. M. (1991, November). Characteristics of words preceding and following a stuttering spasm. Paper presented at the meeting of $t$ the American Speech, Language and Hearing Association, Atlanta, GA.

Trotter, W. D. (1956). Relationship between the severity of stuttering and word conspicuousness. Journal of Speech and Hearing Disorders, 21, 198-201.

Van Riper, C. (1982). The Nature of Stuttering, 2nd ed. Englewood Cliffs, N.J.: Prentice-Hall.

Viswanath, N. S. (1989). Global- and local-temporal effects of a stuttering event in the context of a clausal utterance. Journal of Fluency Disorders, 14, 245-269.

Wells, G. (1979). Effect of sentence structure on stuttering. Journal of Fluency Disorders, $4,123-129$.

Wendahl, R. W. \& Cole, J. (1961). Identification of stuttering during relatively fluent speech. Journal of Speech and Hearing Research, $4,281-286$.

Williams, D. E. (1957). A point of view about "stuttering. Journal of Speech and Hearing Disorders, 22, 390-397. 
Wingate, M. E. (1964). A standard definition of stuttering. Journal of Speech and Hearing Disorders, 29, 484-489.

Wingate, M. E. (1967). Stuttering and word length. Journal of Speech and Hearing Research, 10, 146-152.

Wingate, M. E.(1988). The Structure of Stuttering, a

Psycholinguistic Analysis. New York, Springer-Verlag.

Young, M. A. (1964). Identification of stuttering during relatively "fluent" speech. Journal of Speech and

Hearing Research, 7, 302-303). 
APPENDIX A

83 SENTENCES READ TWICE BY EACH SUBJECT FROM WHICH WORDS STUTTERED IN ONE READING BUT NOT THE OTHER WERE SELECTED INTO THE DATA CORPUS PENDING SPECIFIED EXCLUSION CRITERIA 


\section{SENTENCES FOR PHONETIC INVENTORY}

1. Some people reason that seeing is believing.

2. They feel they are frequently deceived.

3. Bill saw a big pickerel swimming in the ripples.

4. He licked his lips in anticipation of a delicious fish dinner.

5. The agent remained away all day.

6. Late at night he made his way to the place where the sailors stayed.

7. Special regulations were necessary to help the selling of eggs.

8. Several Senators expressed pleasure.

9. Sally banged the black sedan into a taxicab.

10. It was badly damaged by the crash.

11. I am unable to understand my Uncle Gus.

12. He mutters and mumbles about nothing.

13. John started across the yard toward the barn.

14. His father remarked calmly that he'd better not wander too far.

15. Is shaw the author of "Walking on the Lawn"?

16. I thought it was Walter Hall.

17. Don't go home alone in the snow.

18. You'll be cold and soaked and half frozen.

19. Captain Hook pushed through the bushes to the brook. 
20. From where he stood it looked like an ambush.

21. As a rule, we go canoeing in the forenoon.

22. The pool is too cool in June.

23. Hugh refused to join the musicians' union.

24. His excuse was viewed with amusement.

25. Fowler wants to plow all the ground around his house.

26. Somehow I doubt if the council will allow it.

27. The tile workers were fighting for higher prices and more time off.

28. They tried to drive back the strike-breakers.

29. The boys toiled noisily in the boiling sun.

30. They enjoyed the work that Roy avoided.

31. First the girls turned on the furnace.

32. Then they worked on burning the dirty curtains.

33. I'Il undertake it sooner or later.

34. Perhaps after another summer is over, in september or October.

35. Our barn is covered with brilliant red roses.

36. The broad crimson roof draws admiring crowds from far and near.

37. Lawyer Clark held his little felt hat and his black gloves in his lap.

38. He silently placed the will on the table.

39. Mr. Miller had climbed many mountains. 
40. But the chasm before him was the mightiest in his memory .

41. Laden down by their burdens, Dan and Ned ran from the barn into the open.

42. The tornado was not far distant.

43. The monks had no inkling that anything was wrong.

44. Suddenly the strong tones of the gong rang out.

45. Did you ever speculate on the uses of the familiar onion?

46. On the value of a yellow yam.

47. Wait until the weather is warm.

48. Then everyone will want to walk in the woods.

49. "What is that?" he whispered. Somewhere from the left came the whistle of a bobwhite.

50. Hurry back anyhow, Harry.

51. It will help if you only hear half the rehearsal.

52. Part way up the slope above the pool was a popular camping spot.

53. Many people stopped there for picnic suppers.

54. The British were not bothered about the robbery.

55. They believed they could bribe the Arab to betray his tribe.

56. After waiting for twenty minutes the train left the station.

57. The excited recruits sat and talked all night. 
58. The doll's red dress was soiled and muddy.

59. But the ragged child hugged it adoringly.

60. Old Katy had a particular dislike for hawks and crows.

61. She called them "wicked creatures."

62. The big dog began to dig under the log.

63. Gary forgot his hunger and grabbed his gun.

64. "For breakfast," said father, "I find that coffee is

the staff of life.

65. Grapefruit is a food for infants.

66. I believe I'll save this heavy veil.

67. The vogue might be revived eventually.

68. We thought that the theory was pathetic.

69. But we had faith that something would lead to the truth.

70. My father finds it hard to breathe in this weather.

71. Even the heather withers.

72. The successful student does not assume that class exercise is sufficient.

73. He also practices by himself outside.

74. My cousin's play "The Zero zone" is amusing.

75. But it won't be chosen for a prize because it doesn't deserve it.

76. The fishing ship was in shallows near the shore.

77. In one motion a wave crushed it on the shoal.

78. I make no allusion to sabotage. 
79. But an explosion near that garage is unusual.

80. Mitchell was a righteous old bachelor.

81. He watched for a chance to chase the children out of his orchard.

82. All but Judge Johnson pledged allegiance to the legislation.

83. He objected that it was unjust to the soldiers. 
APPENDIX B

DATA CORPUS FOR SUBJECT NM 
DATA CORPUS LEGEND

\begin{tabular}{|c|c|}
\hline SW & Stuttered Word \\
\hline 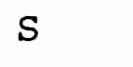 & Sentence Number \\
\hline $\mathrm{R}$ & Reading Number \\
\hline I & Inclusion $(\mathrm{Y} / \mathrm{N})$ \\
\hline $\mathrm{RE}$ & Reason Excluded \\
\hline $\mathrm{P} / \mathrm{E}$ & $\begin{array}{l}\text { Preceding Word } \\
\text { Following Word }\end{array}$ \\
\hline ms. & Milliseconds (duration measurement) \\
\hline Code & $\begin{array}{l}\text { BS BSTUT (Before the Stuttered Word; } \\
\text { nonfluent sample) }\end{array}$ \\
\hline & $\begin{array}{l}\text { BN BNSTUT (Before the Nonstuttered Word; } \\
\text { matching fluent sample) }\end{array}$ \\
\hline & $\begin{array}{ll}\text { AS } & \text { ASTUT (After the Stuttered word; } \\
\text { nonfluent sample) }\end{array}$ \\
\hline & $\begin{array}{l}\text { AN ANSTUT (After the Nonstuttered Word; } \\
\text { matching fluent sample) }\end{array}$ \\
\hline $\mathrm{F} / \mathrm{NM}$ & Filename \\
\hline BS & $\begin{array}{l}\text { Reason Excluded: Occurred at the beginning of a } \\
\text { sentence or syntactic unit }\end{array}$ \\
\hline ES & $\begin{array}{l}\text { Reason Excluded: Occurred at the end of a sentence } \\
\text { or syntactic unit }\end{array}$ \\
\hline BOTH & $\begin{array}{l}\text { Reason Excluded: Words were stuttered both in the } \\
\text { fluent and nonfluent sample }\end{array}$ \\
\hline PS & Reason Excluded: Preceded a stuttered word \\
\hline FS & Reason Excluded: Followed a stuttered word \\
\hline MR & Reason Excluded: Misread (reading error) \\
\hline
\end{tabular}


DATA CORPUS FOR SUBJECT NM

\begin{tabular}{|c|c|c|c|c|c|c|c|c|c|}
\hline & $\begin{array}{l}\text { SW } \\
\text { some }\end{array}$ & $\begin{array}{l}S \\
1\end{array}$ & $\mathrm{R}$ & $\begin{array}{l}\mathrm{I} \\
\mathrm{N}\end{array}$ & $\begin{array}{l}\text { RE } \\
B S\end{array}$ & $P / F$ & $\mathrm{~ms}$. & Code & $\mathrm{F} / \mathrm{NM}:$ \\
\hline \multirow[t]{11}{*}{1} & frequently & 2 & 1 & $\mathrm{Y}$ & & are & 317.5 & BS & 02041 \\
\hline & & & 2 & $Y$ & & are & 365.9 & BN & 02042 \\
\hline & & & 1 & $\mathrm{Y}$ & & deceived & 485.8 & AS & 02061 \\
\hline & & & 2 & $\mathrm{Y}$ & & deceived & 575.4 & AN & 02062 \\
\hline & pickerel & 3 & & $\mathrm{~N}$ & Both & & & & \\
\hline & ripples & 3 & & $\mathrm{~N}$ & ES & & & & \\
\hline & anticipation & 4 & & $\mathrm{~N}$ & Both & & & & \\
\hline & delicious & 4 & & $\mathrm{~N}$ & Both & & & & \\
\hline & the & 5 & & $\mathrm{~N}$ & BS & & & & \\
\hline & agent & 5 & & $N$ & PS/FS & & & & \\
\hline & remained & 5 & & $\mathrm{~N}$ & Both & & & & \\
\hline \multirow[t]{10}{*}{2} & he & 6 & 1 & $\mathrm{Y}$ & & night & 419.6 & BS & 06031 \\
\hline & & & 2 & $Y$ & & night & 257.1 & $\mathrm{BN}$ & 06032 \\
\hline & & & 1 & $\mathrm{Y}$ & & made & 441.8 & AS & 06051 \\
\hline & & & 2. & $\mathrm{Y}$ & & made & 236.8 & AN & 06052 \\
\hline & place & 6 & 2 & $\mathrm{~N}$ & MR & "palace" & & & \\
\hline & sailors & 6 & & $\mathrm{~N}$ & Both & & & & \\
\hline & regulations & 7 & & $\mathrm{~N}$ & Both & & & & \\
\hline & were & 7 & & $\mathrm{~N}$ & PS/FS & & & & \\
\hline & necessary & 7 & & $\mathrm{~N}$ & Both & & & & \\
\hline & sedan & 9 & & $\mathrm{~N}$ & Both & & & & \\
\hline \multirow[t]{4}{*}{3} & badly & 10 & 2 & $\mathrm{Y}$ & & was & 179.5 & BS & 10022 \\
\hline & & & 1 & $\mathrm{Y}$ & & was & 300.3 & BN & 10021 \\
\hline & & & 2 & $\mathrm{Y}$ & & damaged & 428.1 & AS & 10042 \\
\hline & & & 1 & $\mathrm{Y}$ & & damaged & 416.7 & AN & 10041 \\
\hline \multirow[t]{6}{*}{4} & understand & 11 & 2 & $\mathrm{Y}$ & & to & 442.6 & BS & 11041 \\
\hline & & & 1 & $\mathrm{Y}$ & & to & 111.4 & BN & 11042 \\
\hline & & & 2 & $\mathrm{Y}$ & & my & 202.8 & AS & 11061 \\
\hline & & & 1 & $\mathrm{Y}$ & & my & 162.2 & AN & 11062 \\
\hline & and & & & $\mathrm{N}$ & PS/FS & & & & \\
\hline & mumb. & & & $\mathrm{N}$ & PS/FS & & & & \\
\hline \multirow[t]{4}{*}{5} & started & 13 & 1 & $Y$ & & John & 594.9 & BS & 13011 \\
\hline & & & 2 & $\mathrm{Y}$ & & John & 464.1 & $\mathrm{BN}$ & 13012 \\
\hline & & & 1 & $\mathrm{Y}$ & & across & 496.5 & AS & 13031 \\
\hline & & & 2 & & & across & 460.4 & AN & 13032 \\
\hline \multirow[t]{3}{*}{6} & remarked & 14 & 1 & $\mathrm{Y}$ & & father & 699.9 & BS & 14021 \\
\hline & & & 2 & $\mathrm{Y}$ & & father & 393.3 & BN & 14022 \\
\hline & & & 1 & $\mathrm{Y}$ & & calmly & 514.7 & AS & 14041 \\
\hline
\end{tabular}




\begin{tabular}{|c|c|c|c|c|c|c|c|c|c|}
\hline & & & 2 & $\mathrm{Y}$ & & calmly & 468.4 & AN & 14042 \\
\hline & forenoon & 21 & & $\mathrm{~N}$ & $E S$ & & & & \\
\hline \multirow[t]{4}{*}{7} & too & 22 & 1 & $\mathrm{Y}$ & & is & 224.5 & BS & 22031 \\
\hline & & & 2 & $\mathrm{Y}$ & & is & 104.6 & $\mathrm{BN}$ & 22032 \\
\hline & & & 1 & $\mathrm{Y}$ & & $\mathrm{cool}$ & 382.8 & AS & 22051 \\
\hline & & & 2 & $\mathrm{Y}$ & & $\mathrm{cool}$ & 453.7 & AN & 22052 \\
\hline \multirow[t]{6}{*}{8} & in & 22 & 2 & $\mathrm{Y}$ & & $\mathrm{cool}$ & 382.8 & BS & 22052 \\
\hline & & & 1 & $\mathrm{Y}$ & & $\mathrm{coOl}$ & 453.7 & BN & 22051 \\
\hline & & & 2 & $\mathrm{Y}$ & & June & 315.4 & AS & 22072 \\
\hline & & & 1 & $\mathrm{Y}$ & & June & 325.4 & AN & 22071 \\
\hline & Hugh & 23 & & $\mathrm{~N}$ & PS & & & & \\
\hline & refused & 23 & & $\mathrm{~N}$ & FS & & & & \\
\hline \multirow[t]{5}{*}{9} & musicians' & 23 & 1 & $\mathrm{Y}$ & & the & 272.2 & BS & 23051 \\
\hline & & & 2 & $\mathrm{Y}$ & & the & 248.1 & BN & 23052 \\
\hline & & & 1 & $\mathrm{Y}$ & & union & 358.3 & AS & 23071 \\
\hline & & & 2 & Y & & union & 314.0 & AN & 22071 \\
\hline & The & 27 & & $\mathrm{~N}$ & BS & & & & \\
\hline \multirow[t]{4}{*}{10} & workers & 27 & 1 & $\mathrm{Y}$ & & tile & 284.9 & BS & 27021 \\
\hline & & & 2 & $Y$ & & tile & 281.7 & BN & 27022 \\
\hline & & & 1 & $\mathrm{Y}$ & & were & 76.4 & AS & 27041 \\
\hline & & & 2 & $\mathrm{Y}$ & & were & 89.3 & AN & 27042 \\
\hline \multirow[t]{5}{*}{11} & work & 30 & 1 & $\mathrm{Y}$ & & the & 271.1 & BS & 30031 \\
\hline & & & 2 & $\mathrm{Y}$ & & the & 79.5 & $\mathrm{BN}$ & 30032 \\
\hline & & & 1 & $\mathrm{Y}$ & & that & 262.7 & AS & 30051 \\
\hline & & & 2 & $\mathrm{Y}$ & & that & 111.3 & AN & 30052 \\
\hline & dirty & & 2 & $\mathrm{~N}$ & MR & "clothes" & & & \\
\hline \multirow[t]{5}{*}{12} & after & 34 & 1 & $\mathrm{Y}$ & & Perhaps & 540.4 & BS & 34011 \\
\hline & & & 2 & $Y$ & & Perhaps & 551.9 & BN & 34012 \\
\hline & & & 1 & $Y$ & & another & 341.4 & AS & 34031 \\
\hline & & & 2 & $\mathrm{Y}$ & & another & 374.9 & AN & 34032 \\
\hline & admiring & 36 & & $\mathrm{~N}$ & Both & & & & \\
\hline \multirow[t]{6}{*}{13} & little & 37 & 1 & $\mathrm{Y}$ & & his & 251.8 & BS & 37041 \\
\hline & & & 2 & $\mathrm{Y}$ & & his & 133.0 & $\mathrm{BN}$ & 37042 \\
\hline & & & 1 & $\mathrm{Y}$ & & felt & 253.3 & AS & 37061 \\
\hline & & & 2 & $Y$ & & felt & 360.6 & AN & 37062 \\
\hline & silent] & 38 & 1 & $\mathrm{~N}$ & MR & (omitted) & & & \\
\hline & climber & 39 & 2 & $\mathrm{~N}$ & MR & "has" & & & \\
\hline \multirow[t]{4}{*}{14} & tornado & 42 & 1 & $\mathrm{Y}$ & & The & 389.5 & BS & 42011 \\
\hline & & & 2 & $\mathrm{Y}$ & & The & 337.7 & BN & 42012 \\
\hline & & & 1 & $Y$ & & was & 366.9 & AS & 42031 \\
\hline & & & 2 & $\mathrm{Y}$ & & was & 288.3 & AN & 42032 \\
\hline \multirow[t]{5}{*}{15} & anything & 43 & 1 & $\mathrm{Y}$ & & that & 180.7 & BS & 43061 \\
\hline & & & 2 & Y & & that & 105.3 & BN & 43062 \\
\hline & & & 1 & $\mathrm{Y}$ & & was & 208.9 & AS & 43081 \\
\hline & & & 2 & $Y$ & & was & 138.9 & AN & 43082 \\
\hline & Suddenly & 44 & & $\mathrm{~N}$ & BS & & & & \\
\hline
\end{tabular}


16 of

17 speculate $45 \quad \begin{array}{lll}2 & Y \\ 1 & Y\end{array}$

$18 \quad$ familiar $2 Y$

18 familiar

bobwhite

rehearsal

a

popular

19 bothered

They

Arab

20 twenty

21 sat

The

muddy

22 ragged

\section{re}

$2 \mathrm{Y}$

adoringly $591 \mathrm{~N}$ ES

Katy

23 his

$6311 Y$

$2 Y$

breakfast
$24 \quad$ I'Il
Y

$1 Y$

$601 \mathrm{~N}$

$1 \mathrm{Y}$

$2 Y$

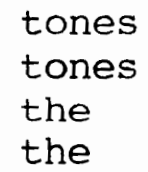

ever

ever

on

on

the

the

onion

onion

ES

ES

PS

FS

not

BS

Both

BS

ES

MR

PS

$6611 Y$

$2 Y$

$1 \mathrm{Y}$
443.0 BS

531.5 BN 44042

86.1 AS 44061

92.3 AN 44062

469.5 BS 45031

465.7 BN 45032

134.4 AS 45051

119.5 AN 45052

285.6 BS 45091

157.0 BN 45092

406.6 AS 45111

381.4 AN 45112 not

about

about

for

for

minutes

minutes

recruits

recruits

and

and

the

the

child

child

"only"

forgot

forgot

hunger

hunger

199.7 BS 54041

249.1 BN 54042

347.9 AS 54061

342.5 AN 54062

182.2 BS 56031

148.0 BN 56032

478.1 AS 56051

427.0 AN 56052

459.2 BS 57031

$426.6 \mathrm{BN} 57032$

187.6 AS 57051

138.9 AN 57052

291.8 BS 59021

152.5 BN 59022

395.3 AS 59041

392.8 AN 59042

409.5 BS 63021

412.9 BN 63022

458.7 AS 63041

378.3 AN 63042

believe 564.7 BS 66021

believe

save
495.7 BN 66022

519.3 AS 66041 


\begin{tabular}{|c|c|c|c|c|c|c|c|}
\hline & & 2 & $\mathrm{Y}$ & save & 477.6 & AN & 66042 \\
\hline something & 69 & 1 & $Y$ & that & 296.5 & BS & 69051 \\
\hline & & 2 & $\mathrm{Y}$ & that & 121.6 & $\mathrm{BN}$ & 69052 \\
\hline & & 1 & $Y$ & would & 155.5 & AS & 69071 \\
\hline & & 2 & $Y$ & would & 186.2 & $A N$ & 69072 \\
\hline sufficient & 72 & 2 & $\mathrm{~N}$ & ES & & & \\
\hline practices & 73 & 2 & $Y$ & also & 581.6 & BS & 73022 \\
\hline & & 1 & $Y$ & also & 568.2 & $\mathrm{BN}$ & 73021 \\
\hline & & 2 & $\mathrm{Y}$ & by & 139.8 & AS & 73042 \\
\hline & & 1 & $Y$ & by & 107.8 & $A N$ & 73041 \\
\hline But & 75 & 1 & $\mathrm{~N}$ & BS & & & \\
\hline orchard & 81 & 2 & $\mathrm{~N}$ & ES & & & \\
\hline legislation & 82 & 1 & $\mathrm{~N}$ & Both/ES & & & \\
\hline objected & 83 & 1 & $\mathrm{Y}$ & $\mathrm{He}$ & 369.3 & BS & 83011 \\
\hline & & 2 & $Y$ & $\mathrm{He}$ & 187.8 & $\mathrm{BN}$ & 83012 \\
\hline & & 1 & $Y$ & that & 228.8 & AS & 83031 \\
\hline & & 2 & $Y$ & that & 249.0 & AN & 83032 \\
\hline
\end{tabular}


APPENDIX C

DATA CORPUS FOR SUBJECT DS 
DATA CORPUS FOR SUBJECT DS

\begin{tabular}{|c|c|c|c|c|c|c|c|c|c|}
\hline & SW & $S$ & $\mathrm{R}$ & I & $\mathrm{RE}$ & $P / F$ & ms. & Code & $\mathrm{F} / \mathrm{NM}:$ \\
\hline \multirow[t]{4}{*}{$I$} & licked & 4 & 2 & $\mathrm{Y}$ & & he & 109.6 & BS & 04012 \\
\hline & & & 1 & $\mathrm{Y}$ & & he & 257.1 & $\mathrm{BN}$ & 04011 \\
\hline & & & 2 & $\mathrm{Y}$ & & his & 178.1 & AS & 04032 \\
\hline & & & 1 & $\mathrm{Y}$ & & his & 229.7 & AN & 04031 \\
\hline \multirow[t]{4}{*}{2} & anticipation & 4 & 1 & $\mathrm{Y}$ & & in & 85.4 & BS & 04051 \\
\hline & & & 2 & $\mathrm{Y}$ & & in & 130.6 & BN & 04052 \\
\hline & & & 1 & $\mathrm{Y}$ & & of & 149.9 & AS & 04071 \\
\hline & & & 2 & $\mathrm{Y}$ & & of & 146.5 & AN & 04072 \\
\hline \multirow[t]{4}{*}{3} & sailors & 6 & 1 & $\mathrm{Y}$ & & the & 114.0 & BS & 06121 \\
\hline & & & 2 & $\mathrm{Y}$ & & the & 86.2 & BN & 06122 \\
\hline & & & 1 & $\mathrm{Y}$ & & stayed & 548.4 & AS & 06141 \\
\hline & & & 2 & $Y$ & & stayed & 554.3 & AN & 06142 \\
\hline \multirow[t]{6}{*}{4} & remarked & 14 & 1 & $\mathrm{Y}$ & & father & 288.0 & BS & 14021 \\
\hline & & & 2 & $\mathrm{Y}$ & & father & 329.2 & BN & 14022 \\
\hline & & & 1 & $\mathrm{Y}$ & & calmiy & 357.7 & AS & 14041 \\
\hline & & & 2 & $\mathrm{Y}$ & & calmly & 362.5 & AN & 14042 \\
\hline & forenoon & 21 & 1 & $\mathrm{~N}$ & ES & & & & \\
\hline & avoided & 30 & 2 & $\mathrm{~N}$ & ES & & & & \\
\hline \multirow[t]{4}{*}{5} & turned & 31 & 1 & $\mathrm{Y}$ & & girls & 319.4 & BS & 31031 \\
\hline & & & 2 & $\mathrm{Y}$ & & girls & 360.7 & BN & 31032 \\
\hline & & & 1 & $\mathrm{Y}$ & & on & 209.6 & AS & 31051 \\
\hline & & & 2 & $Y$ & & on & 184.1 & AN & 31052 \\
\hline \multirow[t]{4}{*}{6} & in & 34 & 2 & $\mathrm{Y}$ & & over & 324.1 & BS & 34062 \\
\hline & & & 1 & $\mathrm{Y}$ & & over & 358.1 & $\mathrm{BN}$ & 34061 \\
\hline & & & 2 & $\mathrm{Y}$ & & September & 530.8 & AS & 34082 \\
\hline & & & 1 & $\mathrm{Y}$ & & September & 490.7 & AN & 34081 \\
\hline \multirow[t]{4}{*}{7} & felt & 37 & 1 & $\mathrm{Y}$ & & little & 288.2 & BS & 37051 \\
\hline & & & 2 & $\mathrm{Y}$ & & little & 228.8 & $\mathrm{BN}$ & 37052 \\
\hline & & & 1 & $\mathrm{Y}$ & & hat & 393.1 & AS & 37071 \\
\hline & & & 2 & $\mathrm{Y}$ & & hat & 275.3 & AN & 37072 \\
\hline \multirow[t]{4}{*}{8} & far & 42 & 1 & $\mathrm{Y}$ & & not & 303.7 & BS & 42041 \\
\hline & & & 2 & $\mathrm{Y}$ & & not & 237.0 & $\mathrm{BN}$ & 42042 \\
\hline & & & 1 & $\mathrm{Y}$ & & distant & 575.5 & AS & 42061 \\
\hline & & & 2 & $\mathrm{Y}$ & & distant & 540.6 & AN & 42062 \\
\hline \multirow[t]{5}{*}{9} & rang & 44 & 1 & $\mathrm{Y}$ & & gong & 478.2 & BS & 44071 \\
\hline & & & 2 & $\mathrm{Y}$ & & gong & 305.7 & $\mathrm{BN}$ & 44072 \\
\hline & & & 1 & $\mathrm{Y}$ & & out & 456.3 & AS & 44091 \\
\hline & & & 2 & $\mathrm{Y}$ & & out & 410.2 & AN & 44092 \\
\hline & yam & 46 & & $\mathrm{~N}$ & & & & & \\
\hline 10 & to & 48 & 2 & $\mathrm{Y}$ & & want & 281.0 & BS & 48042 \\
\hline
\end{tabular}




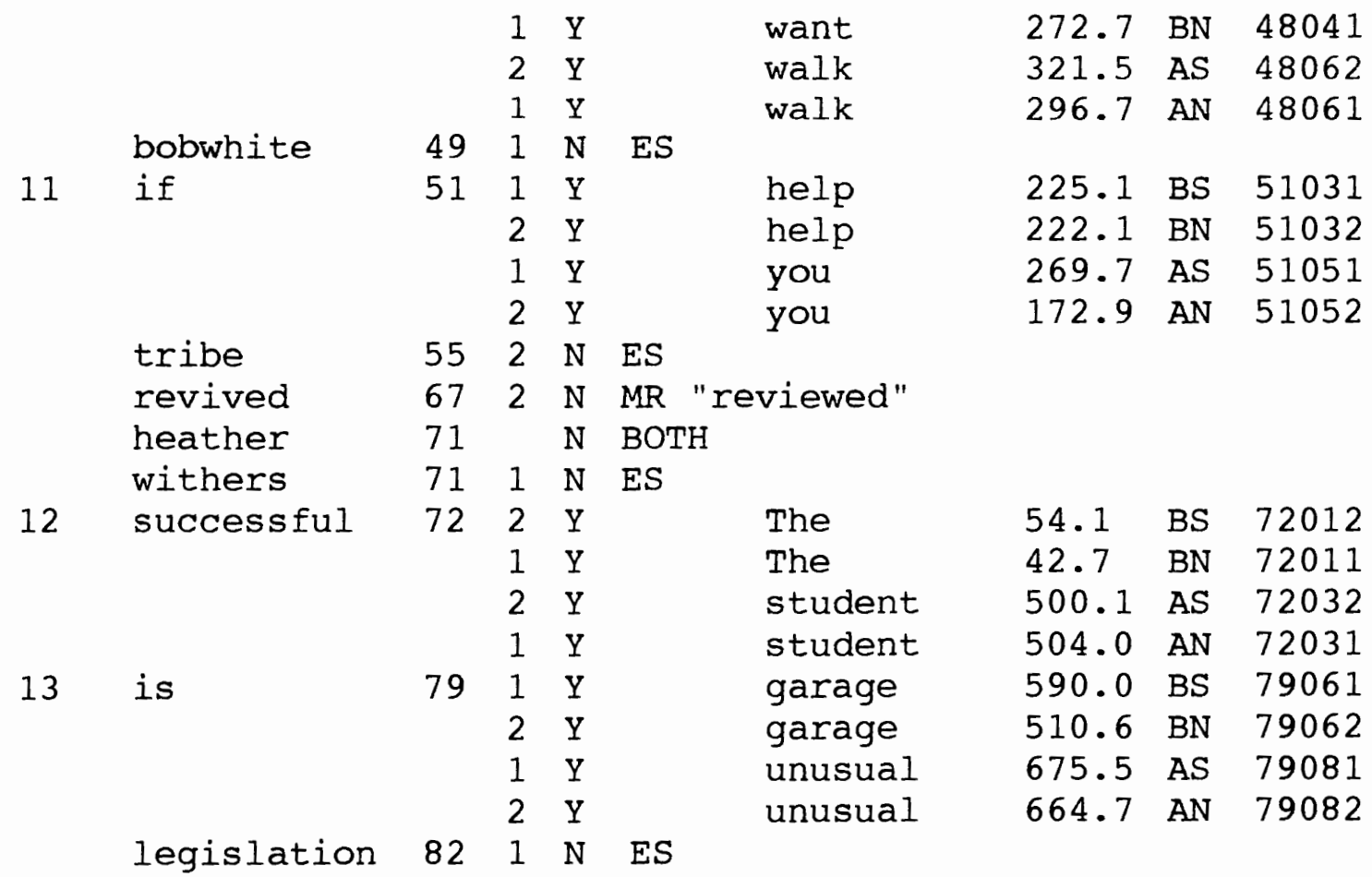

